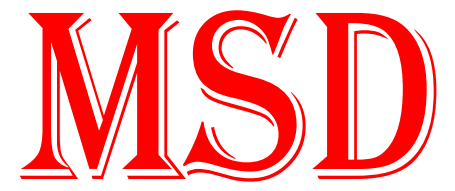

Medical Science and Discovery ISSN: 2148-6832

\section{Case Report Article}

Received 26-11-2021

Accepted 17-12-2021

Available Online: 03-01-2022

Published 30-01-2022

Distributed under

Creative Commons CC-BY-NC 4.0

\section{OPEN ACCESS}

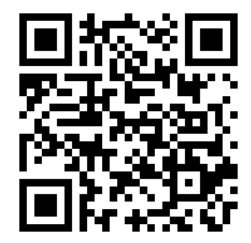

\section{Challenges of elderly patients with short bowel syndrome}

Yasser Abbas Anis Hassan ${ }^{1}$, Maryam Said Rashid Al Hashmi ${ }^{1}$, Salma Amur Abdullah Al Khanjari ${ }^{2} *$

1 Dept. of General Surgery, Khoula Hospital, Muscat, Oman

2 Oman Medical Specialty Board, Muscat, Oman

* Corresponding Author: Salma Amur Al Khanjari E-mail: salma.alkhanjari@ hotmail.com

\section{ABSTRACT}

Objective: This is a case report presenting two elderly patients; one with mesenteric ischemia and the second with gallstone ileus, in which their operative management has resulted in short bowel syndrome (SBS).

Case: This pathology required prolonged post-operative care and monitoring with the management of different related complications.

Conclusion: This case report will cover the pathophysiology, medical and operative management in addition to the acute and chronic complications of SBS.

Keywords: Short Bowel, Syndrome, Mesenteric, Ischemia, Gallstone, Ileus

\section{INTRODUCTION}

Short bowel syndrome (SBS) is the most common cause of intestinal failure in which the individual becomes dependent on parenteral nutrition to maintain health/growth. SBS is defined by the presence of significant malabsorption of macronutrients and micronutrients rather than the length of intestinal resection because of the variable lengths of human small bowel and the different abilities of the remaining bowel to compensate.

SBS caused by postoperative vascular (e.g. acute mesenteric ischemia) and obstructive (e.g. gall stone ileus) catastrophes requiring massive intestinal resection seems to be increasing in incidence and are highlighted in this report's case presentation.

There are several factors that are considered good indicators for having SBS with functional remaining intestine mentioned below:

1) Length of bowel resection: Resection of up to half of the small intestine is generally well tolerated. SBS is likely to develop in patients with loss of two-thirds length of the small intestine. Permanent total parenteral nutrition (TPN) support is likely to be needed in patients with less than $120 \mathrm{~cm}$ of the intestine without colon in continuity and less than $60 \mathrm{~cm}$ with colonic continuity (1).

(The following are the approximated average lengths of different parts of human bowel: duodenum around $25 \mathrm{~cm}$, jejunum around $2 \mathrm{~m}$, ileum around $3 \mathrm{~m}$ and colon around $1.5 \mathrm{~m}$ )

2) Site of bowel resection: jejuno-ileocolic anastomosis has a better prognosis than jejuno-colic anastomosis. End-jejunostomy has the worst prognosis of all. This is due to the different properties of each part of the small bowel which are summarized in table (1). Ileum is better able to adapt after intestinal resection compared with the jejunum (2-5).

The presence of ileocecal valve may be less relevant to outcomes of SBS in adults compared to in children (13). Also, it is worthy to mention the importance of enteral feeding in enhancing intestinal adaptation and reducing the rate of complications (12).

Each of the following nutrients have shown a role in improving adaptation by inducing the release of trophic gastrointestinal hormones: (IV arginine, glutamine, enteral longchain triglycerides, omega-3 fatty acids). Other ways of increasing transit time and absorptive area through surgery will also be discussed in this article. 
Table 1: The nutrients and hormones presented in each part of the bowel includes but is not limited to the corresponding group

\begin{tabular}{|c|c|c|c|c|}
\hline & Absorption & Hormones & Adaptation & Problems if resected \\
\hline Jejunum & $\begin{array}{l}\text { *Carbs } \\
\text { *proteins } \\
\text { *folate } \\
\text { *iron }\end{array}$ & $\begin{array}{l}\text { *motilin } \\
\text { *secretin } \\
\text { *gastrin } \\
\text { *CCK }\end{array}$ & $\begin{array}{l}\text { *Mainly functional: } \\
\text { (changes in transporters \& } \\
\text { enzyme activity) }[6]\end{array}$ & $\begin{array}{l}\text { *gastric } \\
\text { hypergastrinemia \& } \\
\text { hypersecretion [7]. }\end{array}$ \\
\hline Ileum & $\begin{array}{l}\text { *vitamin B12 } \\
\text { *bile acid } \\
\text { *vitamin A,D,E,K }\end{array}$ & $\begin{array}{l}\text { *Peptide YY } \\
\text { *GLP-1 } \\
\text { *GLP-2 } \\
\text { *neurotensin }\end{array}$ & $\begin{array}{l}\text { *Mainly structural: } \\
\text { (villous lengthening, crypt cell } \\
\text { proliferation, muscle } \\
\text { hyperplasia) }[\mathbf{8 , 9}]\end{array}$ & $\begin{array}{l}\text { *fat malabsorption \& } \\
\text { steatorrhea } \\
\text { *oxalate } \\
\text { nephrolithiasis \& CKD } \\
\text { *rapid transit time (lack of ileal break) }\end{array}$ \\
\hline Colon & $\begin{array}{l}\text { *most water \& } \\
\text { electrolytes } \\
\text { *fermented complex } \\
\text { carbs }\end{array}$ & $\begin{array}{l}\text { *peptide YY } \\
*_{\text {*GLP-1 }} \\
{ }^{*} \text { GLP-2 }\end{array}$ & $\begin{array}{l}\text { *slowing transit time } \\
\text { *can absorb up to } 6 \mathrm{~L} \text { of } \\
\text { excess fluid each day }[\mathbf{1 0}] \text {. } \\
\text { *increase gut hormones } \\
\text { production[11]. }\end{array}$ & $\begin{array}{l}\text { *dehydration \& } \\
\text { electrolyte imbalance }\end{array}$ \\
\hline
\end{tabular}

\section{CASE SUMMARY}

\section{$1^{\text {st }}$ Case:}

A 74 years old lady, diabetic, hypertensive, and dyslipidemic on oral medications, no previous surgical history or known allergies. Frequent NSAID taker for lower back disk pain.

She was presented to another government hospital emergency department on 23/1/2021 complaining of 1-day history of epigastric pain that was burning in nature associated with bilious vomiting and constipation for 2 days. She denied chest pain, fever, palpitation, upper respiratory symptoms and dysuria.

Clinically, she was looking in pain. Vitally afebrile, HR, BP and $\mathrm{O} 2$ saturation were all within normal limits. Abdominal exam showed a soft and lax abdomen, with epigastric and paraumbilical tenderness. Bowel sounds were present. ECG done showed normal sinus rhythm with no evidence of ischemia. Laboratory results are shown in the chart below. (see Table 2, date 24/1/21)

Table 2: Abdominal ultrasound was done and showed a normal study with no free fluid. she was admitted there under the impression of drug-induced gastritis.

\begin{tabular}{|lccc|}
\hline & $\mathbf{2 4 / 1 / 2 1}$ & $\mathbf{2 5 / 1 / 2 1}$ & $\mathbf{2 6 / 1 / 2 1}$ \\
\hline Hb & 13 & 13 & 12.8 \\
WBC & 14 & 57 & 59 \\
Neutrophil & 10 & 54 & 52 \\
\hline RFT & normal & normal & Cr 127 U 8.7 \\
CRP & 2 & 203 & \\
ESR & 12 & & \\
LFT & Normal & & \\
troponin & $15-22-30$ & 44 & \\
amylase & $154-210$ & 107 & \\
VBG & Normal & & \\
Lactate & 3.5 & 4.9 & \\
\hline
\end{tabular}

During her stay in the ward, the patient was not tolerating orally, still complaining of abdominal pain unrelieved with paracetamol and tramadol with complain of excessive salivation. Inflammatory markers were noted to increase so it was decided to start her on ceftriaxone.
Later during the day, she spiked a fever (38) and started to be tachycardic (125) so ceftriaxone was upgraded to tazocin and CT abdomen and pelvis was requested, which showed findings suggestive of duodenitis. However, bowel ischemia couldn't be ruled out as the study was of venous phase only. The patient was still complaining of abdominal pain, vomiting, and constipation. Abdominal distention noted, bowel sounds were present. Muscle guarding noted more at the left iliac fossa. Nasogastric tube (NGT) was inserted and $400 \mathrm{ml}$ of fluid was aspirated. The case was discussed and accepted by the general surgery team in our hospital.

On 27/1/21, the patient arrived to our hospital in the same clinical condition, tachycardic (125), with rebound tenderness and guarding mostly over lower abdomen, bowel sounds were audible. Digital rectal exam showed soft stool with no blood. (see laboratory results in Table 3)

Table 3: Blood parameters of the patient.

\begin{tabular}{ccccccc} 
Hb & WBC & Neutrophil & CRP & GFR & Albumin & K \\
11.6 & 45 & 43 & 499 & 43 & 26 & 3.8 \\
\hline
\end{tabular}

CT with IV contrast was proceeded and reported the following: "there is the obliteration of the superior mesenteric artery (SMA) at about $5.7 \mathrm{~cm}$ from its origin, with opacification of the branches proximal to the obstruction. The proximal jejunal loops show good wall enhancement, with no wall thickening; the distal jejunal and ileal loops show poor enhancement with no obvious wall thickening. Atherosclerotic calcification at the origin of the inferior mesenteric artery, which is faintly opacified. The superior mesenteric vein is well opacified. The colon shows good enhancement. Mild free fluid is seen in the abdomen and pelvis. The stomach, small bowel loops, and the colon show no wall thickening or dilatation. No enlarged retroperitoneal, mesenteric or pelvic lymph nodes. Compression fracture of L1 and L2.

Conclusion: SMA thrombosis with associated ischemic ileal loops" 


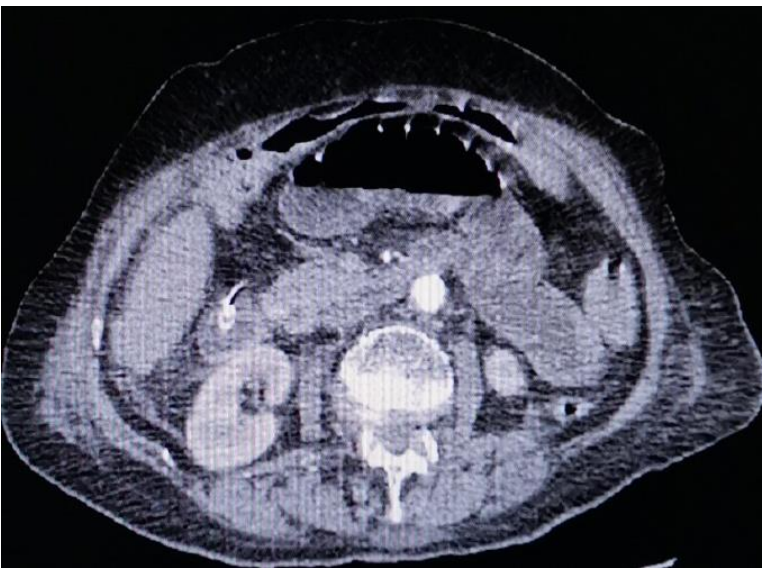

Figure 1: A) enhancing walls of jejunal loops.

Shortly after, the case was decided to crush the emergency operating theater (OT) for (exploratory laparotomy + bowel resection and anastomosis + temporary abdominal closure).

Intra-operative findings were as the following:

- healthy small bowel around $100 \mathrm{~cm}$ measured starting from the ligament of treitz

- the rest of the small bowel was ischemic, along with the cecum

- Ascending colon and the rest of the colon were healthy

Turbid fluid was noted in the abdomen. There was no perforation. The mesentery was palpated at the area of the SMA and transverse incision made to expose the superior mesenteric vessels. The SMA was thrombosed with no pulse or flow. The ischemic and dead bowel was resected. The jejunum was then anastomosed to the colon using GIA stapler 75 side to side. The enterotomy closed using vicryl. The abdominal cavity was irrigated. Drain inserted in the pelvis. Fascia left open for "relook surgery" the next day. The skin closed using interrupted nylon sutures.

On the next day, patient was taken to the OT for relook surgery. Findings were as the following:

- minimal clear fluid in lower abdomen, anastomosis is intact, the color of the small and large bowel looks healthy.

irrigation and suction were done. Fascia, subcutaneous tissue and skin were closed in layers.

The patient stayed in ICU for five days for postoperative care. She was hemodynamically normal without need of inotropic support. Urine output was adequate. She was started on TPN, which was daily increased gradually until she reached her total calorie requirement. $\mathrm{Hb}$, albumin, and electrolytes were corrected as needed. She was weaned off ventilation and extubated successfully. (see laboratory improvement in Table 4)

On $1 / 2 / 21$, she was shifted to HD bed in the surgical ward. Referred to dietitian which advised a special diet for short bowel syndrome case (TPN, with NGT then oral feeds as tolerated)

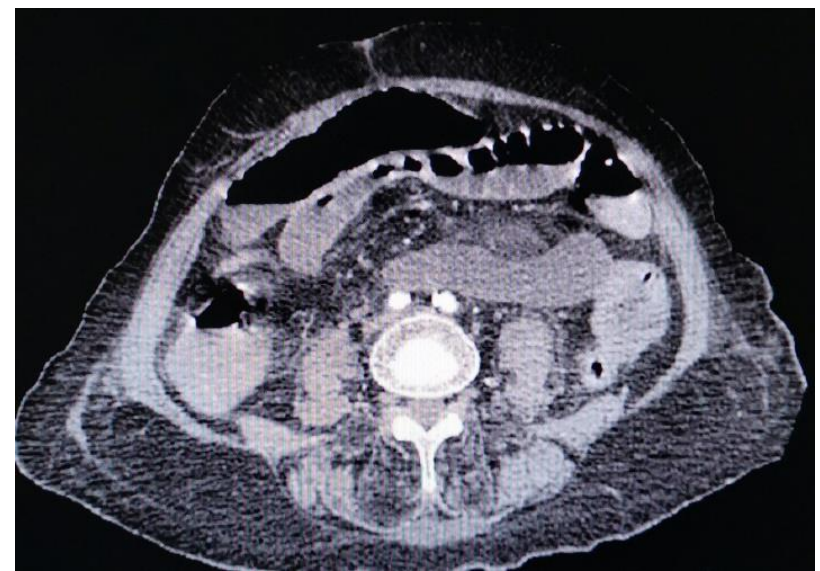

B) un-enhancing ileal loop

Table 4: Blood parameters of the patient after the treatment

$\begin{array}{lccccc} & \mathbf{2 7 / 1} & \mathbf{2 8 / 1} & \mathbf{2 9 / 1} & \mathbf{3 0 / 1} & \mathbf{3 1 / 1} \\ \text { Hb } & 11.5 & 9.5 & 7.6 & 7.7 & 8.5 \\ \text { WBC } & 25 & 16 & 9 & 8 & 8 \\ \text { neutrophil } & 23 & 15 & 8 & 7 & 6 \\ \text { GFR } & 73 & 80 & 73 & 90 & 90 \\ \text { CRP } & 499 & & & & 91 \\ \text { ESR } & & & & & \\ \text { albumin } & 26 & 23 & 22 & & 32 \\ \text { Mg } & & & & & 0.62 \\ \text { phosphorus } & 0.79 & 0.44 & & 1.2 & 0.75 \\ \text { K } & 3.3 & 3.2 & 4.2 & 3.8 & 2.3 \\ \text { RBS } & 9.6 & & & & 31 \\ \text { Urine C/S } & \text { No growth } & & & & \\ \text { Blood C/S } & \text { No growth } & & & & \text { Candida } \\ \text { ET C/S } & & & & & \end{array}$

On 2/2/21, patient was tachypneic, and ABG showed respiratory alkalosis. CXR done showed BL pleural effusion likely from hypoalbuminemia. Pulmonary embolism was ruled out by CTPA.

She was seen by a respiratory therapist whom advised for back-to-back nebulization for the bilateral wheezes and NIV on AVAPS mode in which saturation improved in matter of hours and she started to maintain normal oxygen saturation on room air afterwards.

In the ward, the patient was kept on famotidine, enoxaparin, loperamide (as she started to have watery stool), on daily input-output charting, regular electrolytes $(\mathrm{K}, \mathrm{PO} 4, \mathrm{Mg})$ monitoring and replacement as needed and daily care of laparotomy wound dressing. She was continued on tazocin and physiotherapy.

Tazocin was stopped on 9/2/21 and it was planned to insert a permcath soon to prepare her for discharge with home TPN. (see laboratory results during this period on Table 5) 
Table 5: Blood parameters of the patient

\begin{tabular}{lccc|cc} 
& $\mathbf{1 / 2 / 2 0 2 1}$ & $\mathbf{3 / 2 / 2 0 2 1}$ & $\mathbf{5 / 2 / 2 0 2 1}$ & $\mathbf{7 / 2 / 2 0 2 1}$ & $\mathbf{9 / 2 / 2 0 2 1}$ \\
\hline Hb & 7.5 & 8.9 & 8 & 6.4 & 8 \\
WBC & 16 & 17 & 17 & 6 & 5 \\
Neutrophil & 12 & 12 & 12 & 4 & 3 \\
GFR & 90 & 90 & 90 & 90 & 90 \\
CRP & 50 & 47 & 85 & 93 & 76 \\
Lactate & 1.65 & & & & \\
Albumin & 36 & 40 & & 29 & 31 \\
Mg & 0.64 & 1.24 & 0.88 & 0.66 & 0.84 \\
Phosphorus & 0.46 & 0.66 & 0.74 & & 0.75 \\
K & 2.2 & 4 & 4.1 & 2.7 & 3.4 \\
Urine C/S & & \multicolumn{5}{c}{ Candida } & & \\
Blood C/S & & Candida & & \\
\hline
\end{tabular}

On $12 / 2 / 21$, she was re-started on Tazocin as she started spiking fever multiple times reaching up to (39.4). Central line area was examined and showed no signs of infection or inflammation. Septic workup was sent. CXR was normal.

on 13/2/21, Blood and urine cultures showed yeast. The patient was promptly started on IV Caspofungin.

Her BP was dropping despite IVF boluses. Thus, it was decided to shift her to the ICU to start her on noradrenalin and inflammatory markers were repeated, showing marked increase in CRP, WBC, and neutrophils (see Table 6). Thus, Tazocin was upgraded to Meropenum, and the central line was changed.

On $14 / 2 / 21$, the patient condition was deteriorating, acidotic, urine output was not improving with diuretics and resuscitation; decided for intubation and sedation, noradrenalin requirement was increasing. On the same day, the patient was arrested twice, with second arrest not being able to revive most likely from central line-related septicemia.

Table 6: Increase in CRP, WBC, and neutrophils

\begin{tabular}{lccccc} 
& $\mathbf{1 0 / 2 / 2 0 2 1}$ & $\mathbf{1 1 / 2 / 2 0 2 1}$ & $\mathbf{1 2 / 2 / 2 0 2 1}$ & $\mathbf{1 3 / 2 / 2 1}$ & $\mathbf{1 4 / 2 / 2 1}$ \\
\hline Hb & 8.6 & 9.4 & 9.5 & 8.5 & 9 \\
WBC & 4 & 4 & 4 & 18 & 30 \\
neutrophil & 3 & 2 & 3 & 17 & 23 \\
GFR & 90 & 90 & 90 & 34 & 33 \\
CRP & & 76 & 97 & 277 & \\
lactate & & & & 5.4 & \\
LFT (ALT) & 24 & 25 & 25 & & 193 \\
Mg & 0.6 & 0.6 & 0.4 & & 0.9 \\
phosphorus & 0.72 & 0.8 & & & 1.52 \\
K & 3.8 & 3 & 3.6 & 3.7 & 3.6 \\
Urine C/S & & \multicolumn{5}{c}{ Candida } \\
Blood C/S & & Candida & & \\
\hline
\end{tabular}

\section{$2^{\text {nd }}$ Case:}

Eightly years old Indian female, known case of diabetes mellitus; presented to a private clinic with 2 -week history of abdominal pain mainly in the right upper quadrant and discharged from there with antibiotics after diagnosing her with biliary colic. four days later, she presented again there with severe abdominal pain associated with vomiting, so they did for her CT abdomen, which showed gall stone ileus (see figure 2); she was sick and hemodynamically unstable. Thus, she was referred to us.

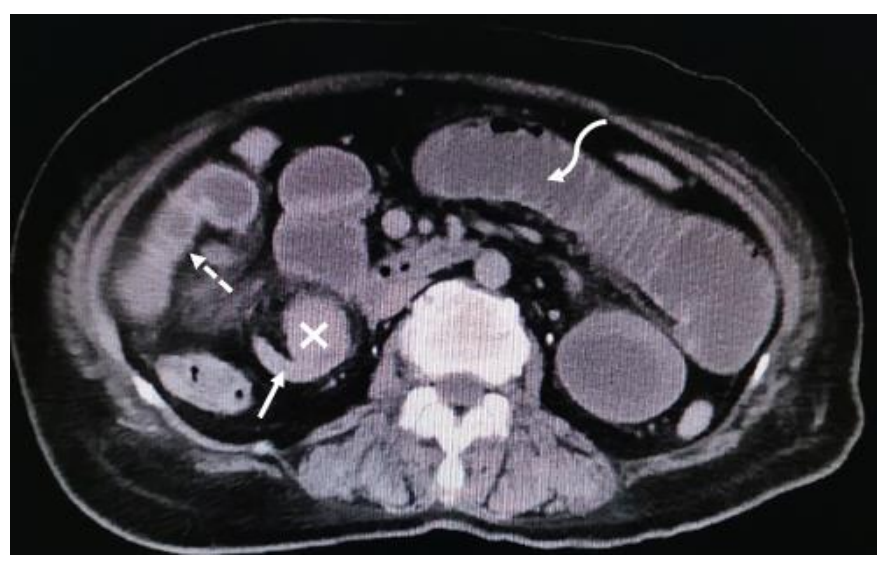

Figure 2: gallstone ileus. The stone (x), contracted distal ileum (straight line arrow), proximal ileal loop (dotted arrow), dilated jejunal loop (curved arrow)

On presentation to our hospital emergency department (on 2nd of February, 2021), the patient was hemodynamically unstable; BP was 78/52, HR was 120 , RR was 28 , febrile and GCS was low (E4V3M5).

Clinically, the patient looked lethargic, disoriented and dehydrated; physical examination revealed distended abdomen, soft and tender all over. Bowel sounds were absent. Rectal tube was inserted, and fecal matter came out of it (brownish fluid), foleys catheter was inserted from which concentrated urine was seen.

The patient was kept on oxygen mask, started resuscitation with $1 \mathrm{~L}$ fast normal saline (NS) boluses, NGT was inserted, the patient started on Tazocin, the right external jugular line was inserted, and blood was collected and resulted (see table 7). The patient was kept NPO and planned for emergency exploratory laparotomy.

Table 7: Blood parameters of the patient

\begin{tabular}{|cccccc|}
\hline Hb & WBC & neutrophil & CRP & GFR & Na \\
\hline 11.5 & 28 & 24.4 & 145 & 47 & 127 \\
\hline K & Urine C/S & lactate & Blood C/S & amylase \\
\hline 5.1 & negative & 4 & GPB & 86 \\
\hline
\end{tabular}

Our impression was intestinal obstruction +/- sepsis. After resuscitation with NS boluses, HR and BP improved. The patient was shifted to the OT for exploratory laparotomy. Intra-operative findings were as the following:

- moderate amount of turbid fluid encountered

- upper abdomen appeared healthy with part of omentum sealing the gall bladder

- obstructing calculus noted around $5 \mathrm{~cm}$ proximal to ileocecal valve

- gangrenous small bowel $(75 \mathrm{~cm}$ distal to duodenojejunal flexure up to $5 \mathrm{~cm}$ proximal to ileocecal valve) resected using linear GI anastomosis stapler without anastomosis

- thorough warm saline wash given utilizing 3 liters

The anastomosis was not done during the same surgery as the patient was on the maximum dose of inotropes in the surgery, so the abdomen was left open for a second look later on; Ushape sterile plastic drape used to cover omentum, padded dressing and opsite applied. 
The post-operative finding was gall stone ileus with resultant small bowel ischemia (see figure 3 and figure 4). After that, the patient was shifted to the ICU, kept NPO, and NGT was kept on free drainage. She was planned to be started on TPN as earliest as possible.

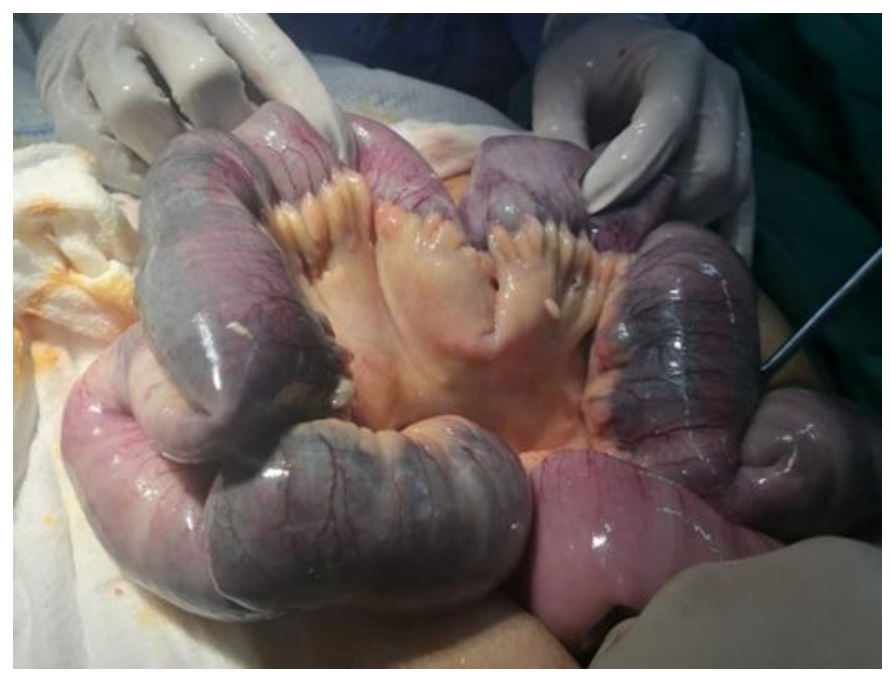

Figure 3: ischemic/gangrenous small bowel

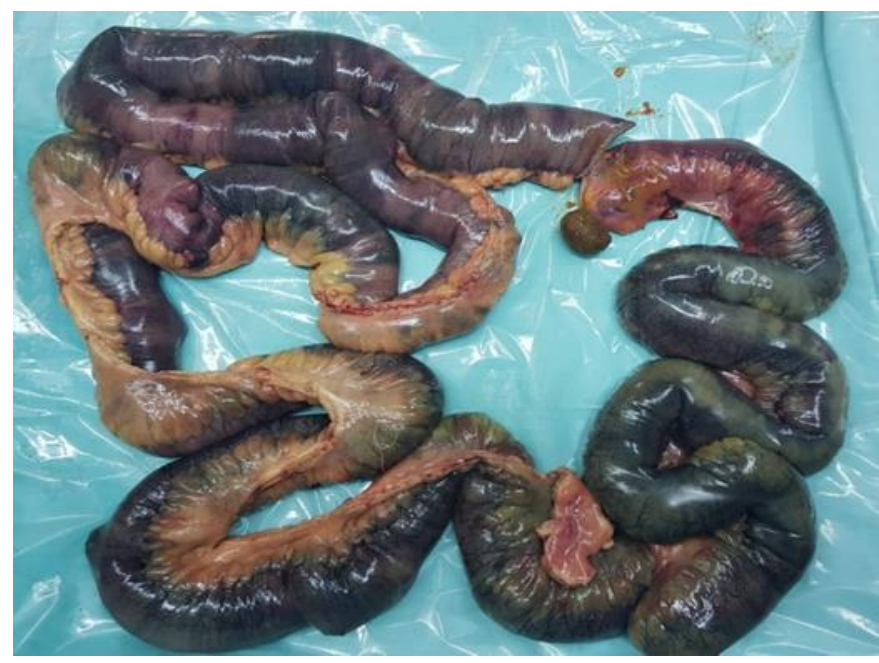

Figure 4: stone in the terminal ileum

The patient showed slight improvement after the surgery. She was kept in ICU, intubated and ventilated with $\mathrm{FiO} 2$ of $40 \%$ and PEP of 5, maintaining BP with NA of $0.3 \mathrm{mcg} / \mathrm{kg} / \mathrm{min}$, sedated with midazolam and fentanyl. However, on the second post-operative day she started to deteriorate in terms of an increase in the inotropic support and she was febrile; labs showed metabolic acidosis with a lactate of 1.9 and an increase in the WBC counts (Table 8), so the decision was made to upgrade tazocin to meropenum and to take the patient to operation room for relook laparotomy eirlier than initially planned.

The patient was taken to the OT for relook and bowel anastomosis. Intra-operative findings are mentioned below:

Bowel appeared normal; no further ischemia noted

Tried to reach gall bladder, however this was not possible due to the tight adhesions

Ascending colon and cecum mobilized and cecum together with ileocecal valve and remaining ileal stump resected with GI anastomosis stapler
The remaining jejunal loop (around $75 \mathrm{~cm}$ ) anastomosed to ascending colon side to side using GIA linear stapler, completed using 3/0 vicryl

- $\quad$ Two drains were inserted and positioned, one in the right paracolic gutter and one in the pelvis skin closure

Mass closure with number 1 loop nylon followed by

On the next three post-operative days: patient was in ICU intubated, ventilated, $\mathrm{FiO} 2$ of $35-40 \%$ and PEEP of 5 , maintained BP with NA (0.1 to 0.4$)$ and was tapered down till stopped, maintained adequate urine output, kept NPO and started on TPN, kept on pneumatic leg compression and Clexane (which was stopped later due to decreasing platelet counts). Wound swab culture was positive for Enterococcus raffinose. She was referred for daily chest physiotherapy and kept on regular monitoring of platelets, magnesium, phosphorus, calcium, albumin, and RBC with replacement of each as needed. The patient was still not passing motion with sluggish bowel sounds; sedatives were stopped however patients GCS remained low (E2VtM1).

On $7 / 2 / 21$, the patient had an episode of desaturation, Fraction of inspired oxygen ( $\mathrm{FiO} 2)$ was increased from $40 \%$ to $50 \%$, NA restarted with dose of $0.08 \mathrm{mcg} / \mathrm{kg} / \mathrm{min}$. thus, patient was started on ipratropium, mucolytic agents and was kept on extensive chest physiotherapy of at least three times per day. Chest x-ray ordered noted air under diaphragm, which was contributed as normal finding during the first postoperative week. She passed motion. Abdominal pressure measured which was normal all through.

On the next four days in ICU, weaning from ventilation started, and NA was tapered down till stopped. Claxane was restarted as platelet counts were noted to improve. Patient was having diarrhea; abdominal pressure was normal. ET C/S was positive for Acromobacter. Wound care was followed up daily by wound management nurse and the drains output were daily monitored. The patient was kept on a ripple mattress to prevent pressure ulcers and was kept on extensive chest physiotherapy. She was successfully extubated and fully regained her consciousness (E4V5M6), and was shifted out of ICU to HD bed.

On $12 / 2 / 21$, the patient was in HD alert and oriented, was maintaining her $\mathrm{O} 2$ saturation with $4 \mathrm{~L} \mathrm{O} 2 / \mathrm{min}$, white cell counts were trending up, but CRP was noted to decrease (Table 9). An abdominal surgical wound was noted to have greenish discharge in the lower part suggesting the possibility of biliary content. CXR was ordered and showed significant air under the diaphragm (see figure 5).

CT abdomen with IV and oral contrast was urgently done and showed a significant amount of pneumoperitoneum with no apparent oral contrast leak at the site of anastomosis, mild free fluid seen scattered in the abdomen and pelvis with peritoneal fat stranding. Micro perforation and anterior wall leakage cannot be excluded (see figure 6). Pt was decided to undergo urgent exploratory laparotomy for the possibility of an anastomotic leak. 
Table 8: She was febrile; labs showed metabolic acidosis with a lactate of 1.9 and an increase in the WBC counts

\begin{tabular}{|c|c|c|c|c|c|c|c|c|c|}
\hline & 2-Feb & 2-Mar & 2-Apr & 2-May & 2-Jun & 2-Jul & 2-Aug & 2-Sep & 2-Oct \\
\hline Hb & 12.4 & 9.2 & 9 & 8.7 & 8.3 & 8.1 & 9.6 & 8.5 & 8.3 \\
\hline WBC & 12 & 22 & 12 & 13 & 17 & 17 & 12 & 10 & 11 \\
\hline neutrophil & 11 & 20 & 11 & 12 & 14 & 15 & 10 & 8 & 9 \\
\hline platelet & 150 & 125 & 60 & 40 & 40 & 47 & 76 & 100 & 125 \\
\hline GFR & 64 & 55 & 42 & 41 & 37 & 42 & 48 & 58 & 81 \\
\hline CRP & 145 & & 172 & & & 112 & 96 & 106 & \\
\hline ALT, ALP & 64,115 & 25,90 & & & & 8,260 & & 8,230 & \\
\hline albumin & 23 & 19 & & & & 33 & & 31 & \\
\hline Mg & & & 0.69 & & 0.8 & 0.6 & & 0.8 & \\
\hline phosphorus & & & 0.47 & & 0.39 & 0.7 & & 1.23 & \\
\hline $\mathbf{K}$ & 4.4 & 4.2 & 3 & 3.7 & 2.5 & 3 & 3.7 & 2.8 & 3.3 \\
\hline Urine C/S & No growth & & & & & & & & \\
\hline wound $\mathrm{C} / \mathrm{S}$ & & & & Enterococcus raffinosus & & & & & No growth \\
\hline ET C/S & Acromobacter & & & & & cromobacter & & & \\
\hline D dimer & & 11 & & & & & & 12 & \\
\hline
\end{tabular}

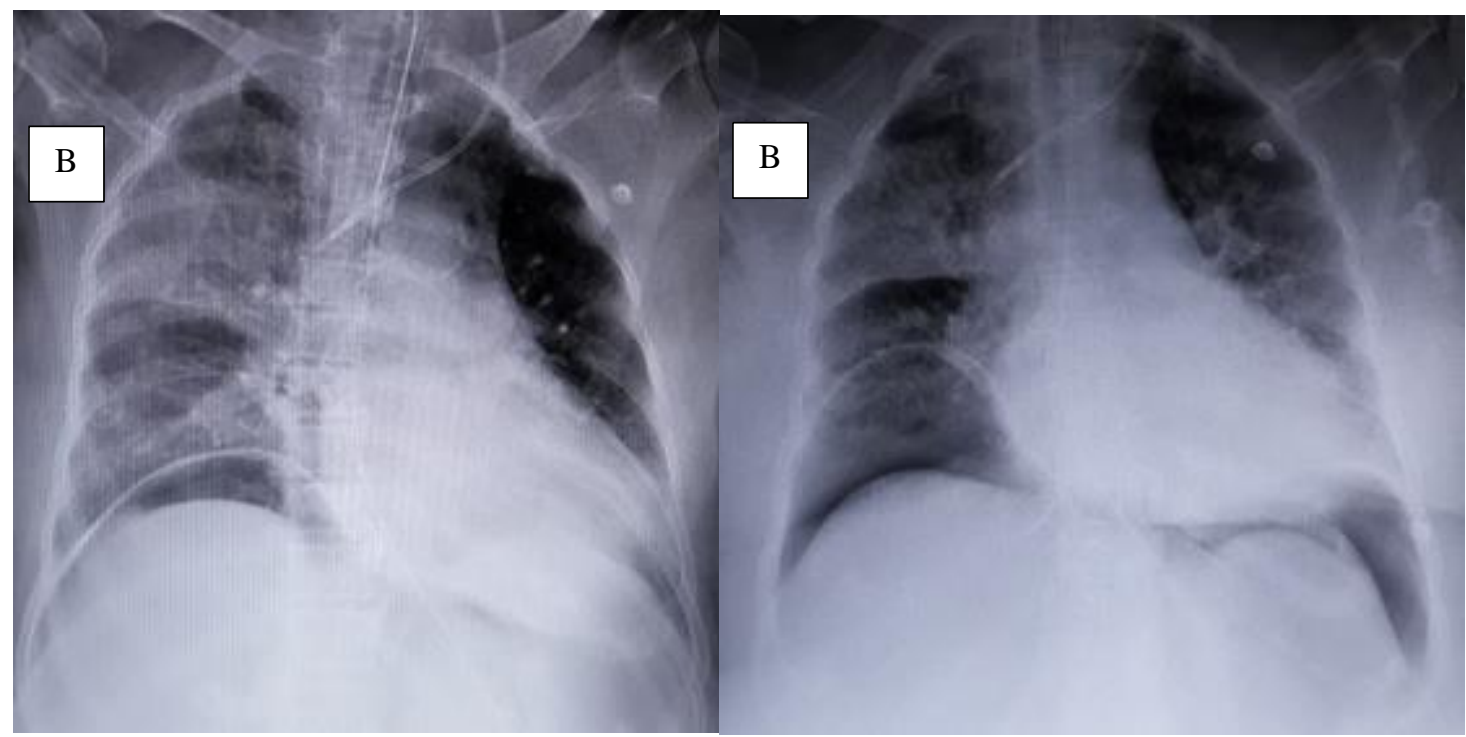

Figure 5: CXR: Air under diaphragm. A) on 7/2/21. B) on 13/2/21.

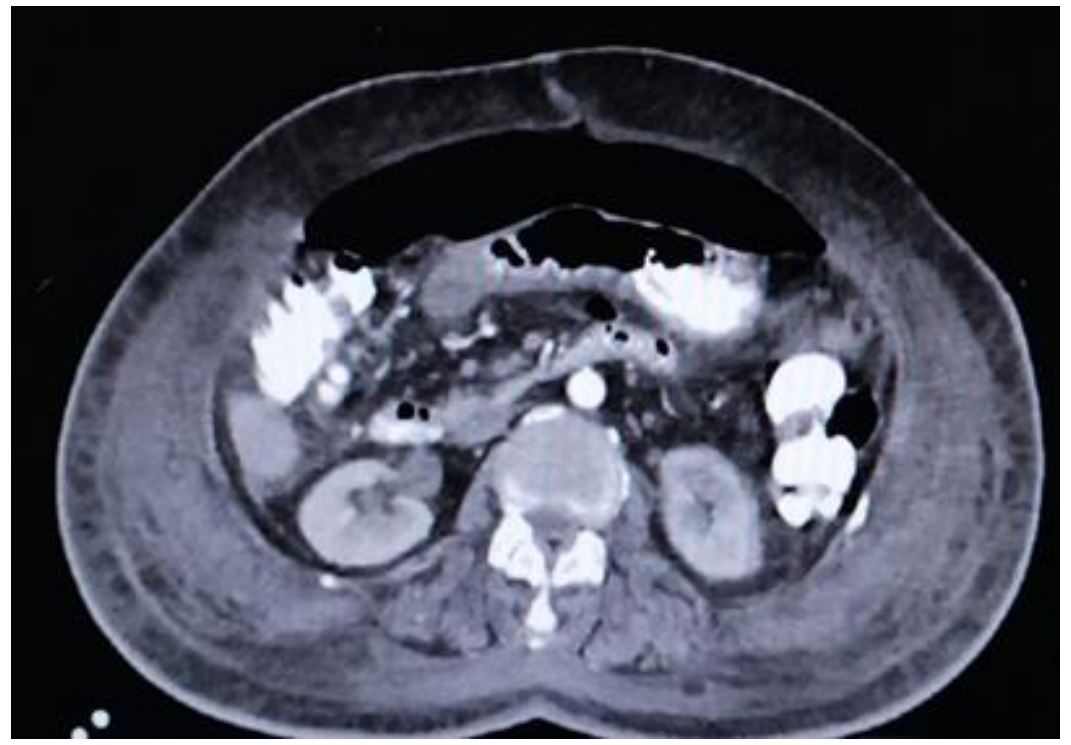

Figure 6: CT scan of abdomen showing pneumoperitoneum 
Table 9: Patient was in HD alert and oriented, was maintaining her $\mathrm{O} 2$ saturation with $4 \mathrm{~L} \mathrm{O} 2 / \mathrm{min}$, white cell counts were trending up, but CRP was noted to decrease

\begin{tabular}{|c|c|c|c|c|c|c|c|c|c|c|}
\hline & 2-Nov & 2-Dec & $13 / 2$ & $14 / 2$ & $15 / 2$ & $16 / 2$ & $17 / 2$ & $18 / 2$ & $19 / 2$ & $20 / 2$ \\
\hline $\mathbf{H b}$ & 9 & 11 & 12 & 7.5 & 8.6 & 7.4 & 7.7 & 5.9 & 8 & 7.7 \\
\hline WBC & 17 & 25 & 52 & 38 & 27 & 12 & 9 & 11 & 13 & 9 \\
\hline neutrophil & 15 & 22 & 50 & 34 & 24 & 10 & 7 & 8 & 9 & 7 \\
\hline GFR & 90 & 90 & 90 & 90 & 90 & 90 & 90 & 90 & 88 & 90 \\
\hline CRP & 63 & 48 & & 126 & & 154 & & 67 & & \\
\hline ALT, ALP & & 20,208 & & 12,130 & & & & & & \\
\hline albumin & & 26 & & 18 & & & & & & \\
\hline Mg & & 0.57 & & 0.69 & & & 0.62 & & & \\
\hline phosphorus & & & & 1 & & & 0.9 & & & \\
\hline $\mathbf{K}$ & 2.7 & 3.5 & 3.2 & 3.5 & 3 & 3.5 & 3 & 3.5 & 3.6 & 4.5 \\
\hline Urine $\mathrm{C} / \mathrm{S}$ & & & candida & & & & & & & \\
\hline
\end{tabular}

On $13 / 2 / 21$, the patient was shifted to the OT, operative findings were as the following: pus was seen in the anterior abdominal wall which was sent for culture, washing of abdominal wall done properly before opening the abdominal cavity.

Upon opening the abdominal cavity, the purulent intraabdominal collection was seen which was also sent for culture.

Exploration of the four quadrants was done carefully as the bowel was adhered intensely to the omentum and the remaining colon.

Careful digital separation of the adherence done between the small bowel and the colon discovering biliary leak at the site of anastomosis (ileo-colic) with unhealthy looking small bowel and pale looking colon.

Linear cutter was used to resect the anastomosis between the ascending colon and the jejunum.

A handsewn anastomosis was done between the jejunum and the transverse colon and the remaining part of the small bowel was approximated around $65 \mathrm{~cm}$ from the duodenojejunal junction.

The patient shifted to ICU intubated, ventilated, sedated and on NA support.

TPN was re-started. Next day, patient was started on ventilatory weaning process that was soon terminated as she appeared to be septic, desaturated on ASV ventilatory mode on trial of weaning.

Septic work up sent showed candida in urine and blood cultures so the patient was promptly started on IV Caspofungin which was later downgraded to fluconazole according to culture's sensitivity.

TPN was withheld temporarily, which was resumed the next day. Lactate was 1.6, NA was being tapered down. Sedations stopped. NGT and abdominal drain output were monitored regularly.
Ventilatory weaning progressed well until she started to develop per-rectal bleeding with clots on 18/2/2021. Coagulation profile was sent and showed normal results. She began to spike fever in the same day. Clexane was withheld, and the patient was started on omeprazole infusion $8 \mathrm{mg} /$ hour. $\mathrm{Her} \mathrm{Hb}$ dropped from 7.7 to 5.9 despite transfusing her with two units of packed RBC. Urgent mesenteric computed tomography angiography was requested, which showed: "no active bleeding that could be seen"

As mesenteric CTA was not successful in determining and controlling the site of bleeding, it was decided to go for urgent upper and lower endoscopy, which was done in the same day. Findings are mentioned below:

\section{OGD was normal, no bleeding source was found}

Colonoscopy: scoped till proximal to the anastomotic line (jejuno-transverse colon anastomosis). The colon was found full of blood with clots. The bleeding area was clearly seen at anastomotic line, which is controlled with one endoscopic clip and injection of adrenaline $25 \mathrm{ml}$ (each $1 \mathrm{ml}$ diluted in $9 \mathrm{ml}$ saline) so total given $2.5 \mathrm{mg}$. afterwards, no more bleeding noticed. Flushing was done and no more accumulation of blood was seen.

Later on, the patient was doing well, there was no more PR bleed and her $\mathrm{Hb}$ stabilized. There was melena but no fresh bleeding or clots. She was continued on ICU care: started NGT "Jevity" feeding formula on top of TPN, which later was changed to partial TPN, continued course of meropenem and fluconazole; blood transfusion, albumin, and electrolyte correction (magnesium, potassium, and phosphorus) were carried out as needed. Extensive chest physiotherapy, DVT prophylaxis by pump machine and daily abdominal wound care (Negative pressure wound therapy (NPWT)) was applied to decrease wound discharge and to aid in wound healing). She spiked once on 21/2/21 in which the central line was removed and tip sent for culture and sensitivity. Inotropes and sedations were stopped, patients' GCS improved gradually. She kept on loperamide for seven days. The patient was extubated successfully and shifted to the surgical ward HD on 4/3/2021. 
In the ward, the patient started to take orally, TPN was being reduced gradually and kept on oral electrolyte replacement

A greenish discharge was noted in the lower part of the surgical wound. Our impression was enterocutaneous fistula and we ordered CT, which showed a large collection around the jejuno-colic anastomotic site with extravasated oral contrast from the anastomosis so the patient was kept NPO, started on octreotide, US-guided drainage by interventional radiologist was done and sample sent for culture which later showed positivity for MDR actinobacter and other gram negative bacilli in which microbiologist advised to add tigecyclin and IV septrin.

Later on, the patient was started on oral diet gradually as tolerated, she was seen daily by physiotherapy, both foleys catheter and abdominal drain removed, colostomy bag applied over the opening and wound left to heal by secondary intention. Antibiotics were downgraded to ciprofloxacin. She was doing good and was discharged with a home TPN.

\section{DISCUSSION}

In the first case, the remaining healthy small bowel was around $100 \mathrm{~cm}$, and the anastomosis was jejuno-colic. In the second case, healthy small bowel was around $75 \mathrm{~cm}$ and the anastomosis used was also jejuno-colic. In both cases, there was more than two-third loss of the total small bowel length, this, in particular, is the cause of short bowel syndrome (SBS) especially, terminal ileum resection was involved in both cases.

The physiologic course of SBS is divided into the acute phase (first one month) and the adaptation phase (one to two years).

In the acute phase, the management focuses on stabilizing large fluid and electrolyte losses along with maintaining acid/base balance through the following:

IV fluids: 0.9 NS and supplemental potassium and magnesium

IV PPI: To prevent peptic ulcer disease, fluid losses and pancreatic enzymes deactivation

- Parenteral nutrition: once the patient is hemodynamically stable

Continuous enteral feeding: to facilitate intestinal adaptation, thereby accelerating the progression to oral feeding (14).

In the adaptation phase, the management focuses on enhancing the structural and functional changes through the following:

Oral diet: with a colon-in-continuity, a diet high in complex carbohydrates and modest in fat and oxalate is recommended. Simple sugars should be avoided.

Fluids: maintain a urine output of at least $1 \mathrm{~L} /$ day. Hypertonic fluids (e.g. regular soda and fruit juices) should be avoided as it contributes to diarrhea; hypotonic fluids (e.g. water, tea, coffee) should be avoided only in end-jejunostomy patients as they do not contain the sodium or glucose that facilitates the absorption process. 1 to 3 liters of oral rehydration solution is advised daily

Pharmacologic therapy: Oral PPI (twice daily for the first 6 months), antidiarrheal agent (prolongs transit time, discontinue according to the response as in patients with bowel dilation it can worsen diarrhea through bacterial proliferation. Loperamide is frequently used; octreotide is not advised as it interferes with the process of adaptation through inhibiting splanchnic protein synthesis (15-17)).

Bile acid sequestrants (e.g. cholestyramine) should be avoided as they may worsen steatorrhea and fat-soluble vitamin losses.

As the patient begins to tolerate enteral/oral feeds, the process of weaning from parenteral nutrition can be started. Tolerance can be determined by the development of symptoms, weight, electrolytes, and hydration status (daily urine > 1L/day and enteral balance (oral fluid intake minus stool output) between 500 and $1000 \mathrm{~mL}$ per day) (18). Weaning can be achieved by decreasing the daily parenteral nutrition infusion volume equally throughout the week (10-30\% reduction daily). However, lifelong monitoring and supplementation of vitamin B12, fat-soluble vitamins, electrolytes, and trace elements might be needed.

SBS-associated intestinal failure reverses in $50 \%$ of adults within the first two years. If not, then patients might need the following interventions to help them wean and get rid of the lifelong need of parenteral nutrition, especially in those who developed parenteral nutrition related complications:

- GLP-2 analog: Teduglutide (the intestine-trophic hormone that enhances adaptive responses)

- $\quad$ Re-anastomosis of small intestine with colon

In patients with anastomotic strictures (especially those with small intestinal bacterial overgrowth), using of tapering enteroplasty, strictureplasty or serosal patching help preserve remaining intestinal length $(19,20)$.

Autologous gastrointestinal procedures: patients without bowel dilatation can benefit from the following procedures, segmental reversal of the small bowel using reversed segments of either small bowel or colon and the creation of valves; these procedures are contraindicated in patients with small bowel bacterial overgrowth as they slow the transit time. Patients with dilated bowel - usually seen in children with SBS - can benefit from binchi's and serial transverse enteroplasty procedures (see figure 7).

Intestinal transplantation: For patients with advanced liver disease (21).

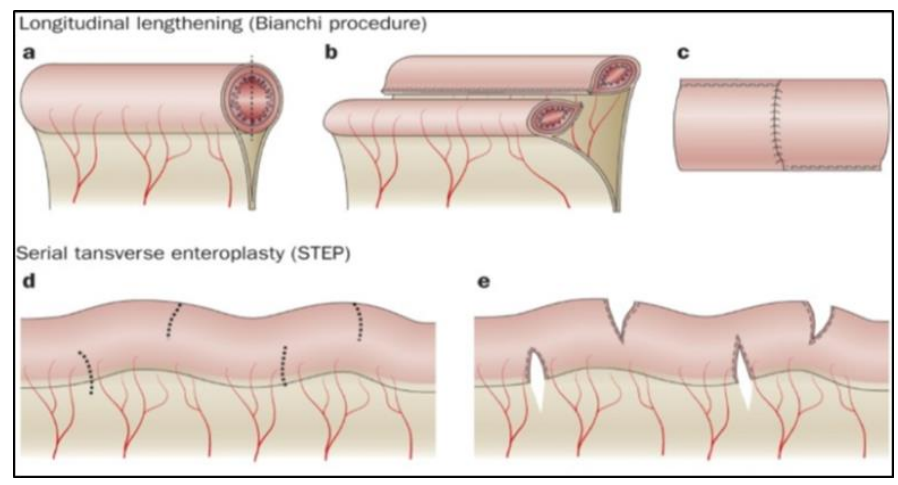

Figure 7: Bowel lengthening procedures for short-bowel syndrome. (22).

SBS related complications are divided into acute and chronic. Acute complications that can occur at any time include watery diarrhea, electrolyte disturbances $(\mathrm{Mg}, \mathrm{K} \& \mathrm{Ca})$, and catheter-related complications. Others are considered as chronic complications (see table 10) 
Table 10: SBS-related chronic complications

\begin{tabular}{|c|c|c|c|}
\hline & Causes & Results & Management \\
\hline peptic ulcer disease & $\begin{array}{l}\text {-loss of inhibitory hormones from } \\
\text { proximal bowel }\end{array}$ & $\begin{array}{l}\text {-fluid losses } \\
\text {-peptic complications } \\
\text {-pancreatic deactivation \& fat } \\
\text { maldigestion }\end{array}$ & PPI \\
\hline $\begin{array}{l}\text { micronutrient } \\
\text { deficiency }\end{array}$ & & & $\begin{array}{l}\text {-vitamin A, D \& E } \\
\text {-vitamin B12 }\end{array}$ \\
\hline $\begin{array}{l}\text { small intestinal } \\
\text { bacterial overgrowth }\end{array}$ & $\begin{array}{l}\text {-small bowel dilation } \\
\text {-loss of ileocecal valve } \\
\text {-acid suppressive medication }\end{array}$ & $\begin{array}{l}\text {-bloating \& flatulence } \\
\text {-abdominal discomfort } \\
\text {-steatorrhea }\end{array}$ & $\begin{array}{l}\text {-antibiotics } \\
\text {-lower carbohydrate diet } \\
\text {-limit the use of antimotility } \\
\text { agents } \\
\text {-limit PPI use in the long term }\end{array}$ \\
\hline $\begin{array}{l}\text { hepatic steatosis and } \\
\text { cholestasis }\end{array}$ & $-\mathrm{TPN}$ & $\begin{array}{l}\text {-steatosis is more common in } \\
\text { adults and usually is benign } \\
\text {-cholestasis is more common in } \\
\text { children and can progress to } \\
\text { cirrhosis }\end{array}$ & $\begin{array}{l}\text {-cyclic parenteral nutrition } \\
\text {-use of enteral nutrition } \\
\text {-ursodeoxycholic acid }\end{array}$ \\
\hline Cholelithiasis & $\begin{array}{l}\text {-biliary stasis ( } \downarrow \text { CCK stimulation) } \\
\text {-bile acid malabsorption \& resultant } \\
\text { increase in cholesterol synthesis }\end{array}$ & -cholecystitis & $\begin{array}{l}\text {-oral/enteral feeds } \\
\text {-prophylactic } \\
\text { cholycyctectomy [23]. }\end{array}$ \\
\hline $\begin{array}{l}\text { metabolic bone } \\
\text { disease }\end{array}$ & $\begin{array}{l}\text {-vitamin D malabsorption } \\
\text {-hypocalcemia } \\
\text {-hypomagnesemia } \\
\text {-metabolic acidosis }\end{array}$ & $\begin{array}{l}\text {-osteoporosis } \\
\text {-osteomalacia } \\
\text {-secondary hyperparathyroidism }\end{array}$ & $\begin{array}{l}\text {-DEXA biannually } \\
\text {-Ca, Mg \& vitamin D } \\
\text { replacement } \\
\text {-IV bisphosphonates }\end{array}$ \\
\hline Nephrolithiasis & $\begin{array}{l}\text {-calcium binds to unabsorbed fatty acids } \\
\text { leaving oxalate free to pass into colon }\end{array}$ & $\begin{array}{l}\text {-calcium oxalate renal stones } \\
\text {-CKD }\end{array}$ & $\begin{array}{l}\text {-low oxalate, low-fat diet } \\
\text {-high fluid intake } \\
\text {-Ca carbonate } 1-4 \mathrm{~g} / \text { day }\end{array}$ \\
\hline D-lactic acidosis & $\begin{array}{l}\text {-bacterial fermentation of unabsorbed } \\
\text { carbs in the colon produces D- lactate }\end{array}$ & $\begin{array}{l}\text {-altered mental status } \\
\text {-slurred speech } \\
\text {-seizures } \\
\text {-ataxia }\end{array}$ & $\begin{array}{l}\text {-low carbohydrate diet } \\
\text {-antibiotics (metronidazole) }\end{array}$ \\
\hline
\end{tabular}

It is important to mention the fact that the patient from first case scenario underwent a surgery free of complications and was clinically and laboratory improving and tolerating oral feeds; thus, was ready to be discharged with home TPN and regular follow up. Unfortunately, she deteriorated from central line associated blood stream infection and died from it. So, it was crucial for us to highlight about the ways of preventing this specific complication out of all and ways of managing it.

The location, duration, and catheter care are important determinants for the development of catheter-related blood stream infection (CRBSI); Hence, some recommendations will be mentioned here for the prevention of CRBSI.

For peripheral venous catheters (PVC), the risk is higher in the lower compared with the upper extremity and higher in the wrist or upper arm compared with the hand $(24,25)$. For central venous catheters (CVC), infection is generally more common with catheters in the femoral and, probably to a lesser degree, internal jugular veins compared with the subclavian vein.

We suggest that PVCs be replaced as clinically indicated rather than at a set time period of three to four days (an exception to this is when catheters are placed during a medical emergency in which it is advised to be replaced as soon as possible) (26).
Vigilant clinical evaluation and assessment of the catheter site should be performed at least every other day; Indications for catheter replacement include purulence, redness and tenderness at the site of insertion; watch for fever and hemodynamic instability. we recommend against the use of guidewire techniques to exchange catheters since it increases the risk of blood stream infection. the use of antimicrobialimpregnated catheters is advised. The following site care measures can significantly minimize the incidence of catheter-related infections: hand washing, Full barrier precautions during the insertion procedure, use of chlorhexidine for skin disinfection (the antiseptic should air dry before catheter insertion), Prompt removal of catheters when no longer indicated. For intensive care unit patients, daily chlorhexidine bathing is beneficial. It is advised to use sterile gauze rather than transparent dressings with CVCs.

It is worthy to mention, some important points when managing CRBSI. Indwelling catheters should be removed in the setting of CRBSI due to Staphylococcus aureus, Pseudomonas aeruginosa, fungi, or mycobacteria. Empiric antibiotic therapy in health care settings should include vancomycin to cover MRSA and another antibiotic that covers pseudomonas. Transesophageal echocardiogram should be pursued in the setting of S. aureus bacteremia to rule out infective endocarditis (Exceptions include patients whose fever and bacteremia resolve within 72 hours following catheter removal and have no clinical signs of endocarditis). 


\section{CONCLUSION}

Short bowel syndrome occurs in $15 \%$ of adults undergoing intestinal resection. $50 \%$ of them are able to be entirely weaned from TPN over 2-5 years. Factors like the length and site of bowel resection play an important role in determining the prognosis and outcome.

In the acute phase, it is important to replace fluid and electrolyte losses and to start the patient on parenteral feeding $\&$ PPI once stabilized with the initiation of enteral feeding as soon as tolerated due to its crucial role in enhancing adaptation.

SBS has a lot of complications that have to be dealt with in the short and long term. TPN related liver disease and repeated catheter septicemia are some of the indications for using autologous gastrointestinal procedures and intestinal transplantation; preventing these complications at the first place play the most important role in improving SBS patients' outcome.

\section{Acknowledgement: None}

Author Contributions: SAAK: Concept, Data collection and/or processing, Analysis and/or interpretation, Literature review, SAAK: Writing, Revisions

Conflict of interest: The author declared no potential conflicts of interest with respect to the research, authorship, and/or publication of this article. This research did not receive and specific grant from funding agencies in the public, commercial, or not-for-profit sectors.

Ethical approval: The study was conducted according to the guidelines of the Declaration of Helsinki and approved by Local Ethical Committee.

\section{REFERENCES}

1. Carbonnel F, Cosnes J, Chevret S, Beaugerie L, Ngô Y, Malafosse M, et al. The role of anatomic factors in nutritional autonomy after extensive small bowel resection. JPEN J 1996;20:275-80.

2. Buchman AL, Scolapio J, Fryer J. AGA technical review on short bowel syndrome and intestinal transplantation. Gastroenterology 2003; $124: 1111$.

3. Jeong SH, Lee HJ, Bae HJ, et al. Factors affecting postoperative dietary adaptation in short bowel syndrome. Hepatogastroenterology 2009; 56:1049.

4. Longshore SW, Wakeman D, McMellen M, Warner BW. Bowel resection induced intestinal adaptation: progress from bench to bedside. Minerva Pediatr 2009; 61:239.

5. Thompson JS, Quigley EM, Adrian TE. Factors affecting outcome following proximal and distal intestinal resection in the dog: an examination of the relative roles of mucosal adaptation, motility, luminal factors, and enteric peptides. Dig Dis Sci 1999; 44:63.

6. Buchman AL, Scolapio J, Fryer J. AGA technical review on short bowel syndrome and intestinal transplantation. Gastroenterology 2003; 124:1111.

7. Williams NS, Evans P, King RF. Gastric acid secretion and gastrin production in the short bowel syndrome. Gut 1985; 26:914.

8. McDuffie LA, Bucher BT, Erwin CR, et al. Intestinal adaptation after small bowel resection in human infants. J Pediatr Surg 2011; 46:1045.

9. Schmidt T, Pfeiffer A, Hackelsberger N, et al. Effect of intestinal resection on human small bowel motility. Gut 1996; 38:859.
10. Debongnie JC, Phillips SF. Capacity of the human colon to absorb fluid. Gastroenterology 1978; 74:698.

11. Healey KL, Bines JE, Thomas SL, et al. Morphological and functional changes in the colon after massive small bowel resection. J Pediatr Surg 2010; 45:1581.

12. DiBaise JK, Young RJ, Vanderhoof JA. Intestinal rehabilitation and the short bowel syndrome: part 1. Am J Gastroenterol 2004; 99:1386.

13. Kaufman SS, Loseke CA, Lupo JV, et al. Influence of bacterial overgrowth and intestinal inflammation on duration of parenteral nutrition in children with short bowel syndrome. J Pediatr 1997; $131: 356$.

14. Joly F, Dray X, Corcos O, et al. Tube feeding improves intestinal absorption in short bowel syndrome patients. Gastroenterology 2009; 136:824.

15. Ladefoged K, Christensen KC, Hegnhøj J, Jarnum S. Effect of a long acting somatostatin analogue SMS 201-995 on jejunostomy effluents in patients with severe short bowel syndrome. Gut 1989; 30:943.

16. Nehra V, Camilleri M, Burton D, et al. An open trial of octreotide longacting release in the management of short bowel syndrome. Am J Gastroenterol 2001; 96:1494.

17. O'Keefe SJ, Haymond MW, Bennet WM, et al. Long-acting somatostatin analogue therapy and protein metabolism in patients with jejunostomies. Gastroenterology 1994; 107:379.

18. DiBaise JK, Matarese LE, Messing B, Steiger E. Strategies for parenteral nutrition weaning in adult patients with short bowel syndrome. J Clin Gastroenterol 2006; 40 Suppl 2:S94.

19. Sudan D. Advances in the nontransplant medical and surgical management of intestinal failure. Curr Opin Organ Transplant 2009; $14: 274$.

20. Thompson JS, Sudan DA, Gilroy R. Predicting outcome of procedures to slow intestinal transit. Transplant Proc 2006; 38:1838.

21. Thompson J, Sudan D. Intestinal lengthening for short bowel syndrome. Adv Surg 2008; 42:49.

22. The concept of gut rehabilitation and the future of visceral transplantation. Author: Kareem Abu-Elmagd. Feb. 2015. Gale Onefile health and medicine.

23. Jeppesen PB, Hartmann B, Thulesen J, et al. Glucagon-like peptide improves nutrient absorption and nutritional status in short-bowel patients with no colon. Gastroenterology 2001; 120:806.

24. O'Grady NP, Alexander M, Dellinger EP, et al. Guidelines for the prevention of intravascular catheter-related infections. Centers for Disease Control and Prevention. MMWR Recomm Rep 2002; 51:1.

25. Maki DG, Ringer M. Risk factors for infusion-related phlebitis with small peripheral venous catheters. A randomized controlled trial. Ann Intern Med 1991; 114:845

26. O'Grady NP, Alexander M, Burns LA, et al. Guidelines for the prevention of intravascular catheter-related infections. Clin Infect Dis 2011; 52:e162.

Copyright (C) 2021 The Author(s); This is an open-access article distributed under the terms of the Creative Commons Attribution License (http://creativecommons.org/licenses/by/4.0), (CC BY NC) which permits unrestricted use, distribution, and reproduction in any medium, provided the original work is properly cited. International Journal of Medical Science and Discovery. 